
Military Technical College
Kobry El-Kobbah, Cairo, Egypt.

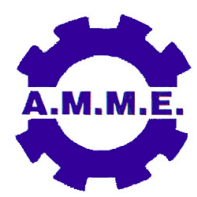

\title{
NICKEL BASE SUPERALLOYS USED FOR AERO ENGINE TURBINE BLADES
}

\author{
A. M. Morad ${ }^{1}$ and Y. M. Shash ${ }^{2}$
}

\begin{abstract}
Nickel base Superalloys service at high temperatures, particularly in the hot zones of gas turbine engine. These materials allow the turbine to operate more efficiently by withstanding higher temperatures. Turbine Inlet Temperature (TIT) depends on the temperature capability of first stage high-pressure turbine blade made of nickel base superalloys exclusively.
\end{abstract}

Single crystal Nickel base turbine blade is free from $\gamma / \gamma$ grain boundaries; boundaries are easy diffusion paths and therefore reduce the resistance of the material to creep deformation.

Experimental investigation carried out by using Different scrap of turbine blades with different chemical compositions were melted aiming to control the chemical composition of the product alloy, leading to a steel alloy called iron base superalloy with nickel content $(24.3 \%)$ and chromium content $(13.2 \%)$ this new alloy has almost the same mechanical properties of nickel base superalloy of higher price. This new alloy can be used for production of turbine blades for small gas turbine engines less than $200 \mathrm{KW}$. Solidification behavior of stepped cast specimen of nickel base superalloy was studded by using three different cast thicknesses size. The results and conclusion of this work show that the higher the cooling rate is the better the mechanical properties. The results also show that the increase of cobalt and titanium contents of nickel base alloy from $1.08 \& 9.31$ and $2.68 \& 10.78$ respectively leads to an increase in ultimate tensile strength, yield strength and hardness. Microstructure investigation of nickel base superalloys was conducted on all samples, the results show the continuous matrix $(\gamma)$ and the primary strengthening phase $(\gamma)$, the microstructure change from dendrite structure to a fine cellular one by increasing titanium percent content.

\section{KEY WORDS}

Superalloys; Nickel base Superalloys; Turbine blades; Single crystal turbine blades.

${ }^{1}$ Egyptian Armed Forces.

${ }^{2}$ Professor, faculty of engineering, Cairo university, Giza, Egypt. 


\section{INTRODUCTION}

A superalloy, or high-performance alloy, is an alloy able to withstand extreme temperatures that would destroy conventional metals like steel and aluminum. Superalloys exhibit excellent mechanical strength and creep resistance at high temperatures, good surface stability, corrosion and oxidation resistance. Superalloys typically have an austenitic face-centered cubic crystal structure. superalloy's base alloying element is usually nickel, cobalt, or nickel-iron. Superalloy development has relied heavily on both chemical and process innovations and has been driven primarily by the aerospace and power industries. Typical applications are in the aerospace industry, e.g. for turbine blades for jet engines. Superalloys are metallic materials for service at high temperatures, particularly in the hot zones of gas turbines. Such materials allow the turbine to operate more efficiently by withstanding higher temperatures. Turbine Inlet Temperature (TIT) depends on the temperature capability of first stage high-pressure turbine blade made of nickel base superalloys exclusively. The largest applications of superalloys are the following: aircraft and industrial gas turbines, rocket engines, space vehicles, submarines, nuclear reactors, military electric motors, chemical processing vessels, and heat exchanger tubing [1].

\section{HISTORY OF NICKEL BASE SUPERALLOY}

Nickel base superalloys were created at approximately the turn of the century with the addition of $20 \mathrm{wt} \% \mathrm{Cr}$ in an $80 \mathrm{wt} \% \mathrm{Ni}$ alloy for electrical heating elements. In the late 1920 s, small amounts of aluminum and titanium were added to the $80 \mathrm{Ni}-20 \mathrm{Cr}$ alloy, with a significant gain in creep strength at elevated temperatures. It soon became apparent that iron and cobalt alloys could be more effectively strengthened by solid-solution additions, while nickel alloys could be strengthened by a coherent phase $\gamma$ Concurrent with these additions, the carbon present in the alloys was identified as having a strengthening effect when combined with other alloying elements to form M6C and M23C6 carbides. Other grain boundary formers, such as boron and zirconium, were added to polycrystalline materials to hold the material together. In the early development time period (about 1926), Heraeus Vacuumschmelze A.G. received a patent for a nickel-chromium alloy that contained up to $15 \mathrm{wt} \% \mathrm{~W}$ and $12 \mathrm{wt} \% \mathrm{Mo}$, thereby introducing the refractory metals into superalloy compositions. The purpose of adding refractory metals was to increase the high-temperature strength of the nickel-base alloy. In the early 1950s, alloys containing about 5 wt\% Mo were introduced in the United States. The commercial exploitation of Mo additions took place in 1955. A cast alloy containing $2 \mathrm{wt} \% \mathrm{Nb}$ was available in the late 1950s. Only one commercially significant alloy uses vanadium; it became available in about 1960. In the early 1960s, tungsten and tantalum were widely accepted for alloying in nickel base alloys. Finally, the demonstration of the effectiveness of rhenium additions in nickel-base alloys occurred in the late 1960s. The original $20 \mathrm{wt} \% \mathrm{Cr}$ level in superalloys was increased to $25 \mathrm{wt} \%$ or higher in some alloys to gain oxidation resistance, but because of its perceived deleterious effect on strength, chromium was reduced to as low as $10 \mathrm{wt} \%$ in favor of aluminum for oxidation protection. However, reducing chromium led to the 
onset of hot corrosion-enhanced oxidation resulting from sodium, sulfur in the fuel, and exhaust gas stream.

The trend toward the increased use of refractory metals is shown in Fig. 1 and Table 1. It is apparent that, based on weight, the refractory metal content of nickelbase alloys tended to increase steadily from the mid-1940s to about 1980 . With this increasing use of refractory metals in superalloys, the concern for the availability of those determined to be strategic, that is, chromium, niobium, and tantalum, becomes apparent.

Table 2 presents a list of several nickel base superalloys that have been used in gas turbine engines or that are emerging as replacements because of the promise of increased operating temperatures and higher efficiencies for the aircraft of the future. These alloys are used in a variety of forms, such as turbine blades, vanes, and disks; compressor components; and ducting components, and they serve a multitude of needs [2].

\section{ALLOYING COMPOSITION OF SUPERALLOYS}

Many of the industrial nickel-based superalloys contain alloying elements, including chromium, aluminum, and titanium, also molybdenum, tungsten, niobium, tantalum and cobalt are also used. Superalloys are a group of $\mathrm{Ni}, \mathrm{Fe}$, and Co base alloys specially designed to operate in the temperature range of 500 to $1100^{\circ} \mathrm{C}$ in jet engines and land-based gas turbines. These alloys are multi component complex alloys which, in addition to $\mathrm{Ni}$, Fe or Co contain varying amounts of $\mathrm{Cr}, \mathrm{Mo}, \mathrm{W}, \mathrm{Nb}$, $\mathrm{Al}, \mathrm{Ti}, \mathrm{Ta}, \mathrm{Re}, \mathrm{Hf}, \mathrm{Zr}, \mathrm{B}$, and $\mathrm{C}$ to obtain the desired strength, oxidation resistance, and corrosion resistance. Superalloys have been under intense and continuing development since the early 1940's [1].

\section{PROPERTIES AND MAIN USES OF SUPERALLOYS}

A Jet engine is the main uses of superalloys, which consists of compressor, shaft, combustion chamber, turbine and exhaust nozzle; Figure 2 shows the layout of the Jet engine, the distribution of pressure and temperature inside the Jet engine is shown in Fig. 3 [3].

The temperature level reaches the maximum in the combustion chamber, where the turbine blades are located. Due to the distribution of temperature and pressure in Jet engine; Fig. 4 shows the alloys and the location of these alloys in the jet engine. It is noticed that nickel base superalloys are positioned just behind the combustion chamber in Rolls Royce jet engine which includes turbine blades [4].

As seen in Fig. 5, the temperature and strength of different alloys have an inverse relationship. In this figure, Ti alloys have the highest strength among other alloys at lower temperatures. However, as the temperature increases the strength of titanium alloys decreases dramatically, while nickel alloys show the best strength at higher temperatures in comparison with other alloys so it uses for production of turbine blades [3]. 
Table 1. Refractory metal content of selected nickel base superalloys and year of Availability [2].

\begin{tabular}{|c|c|c|c|c|c|c|c|c||}
\hline \multirow{2}{*}{ Alloy } & \multicolumn{7}{|c||}{ Nominal refractory metal content, wt\% } & \multirow{2}{*}{ Year* } \\
\cline { 2 - 9 } & $\mathrm{Cr}$ & $\mathrm{Mo}$ & $\mathrm{W}$ & $\mathrm{Nb}$ & $\mathrm{Ta}$ & $\mathrm{Re}$ & $\mathrm{V}$ & \\
\hline Nimonic 80A & 20 & 0 & 0 & 0 & 0 & 0 & 0 & 1942 \\
\hline Waspaloy & 19 & 4.4 & 0 & 0 & 0 & 0 & 0 & 1951 \\
\hline Nimonic 100 & 11 & 5 & 0 & 0 & 0 & 0 & 0 & 1953 \\
\hline M-252 & 20 & 4.0 & 0 & 0 & 0 & 0 & 0 & 1953 \\
\hline Inconel 713C & 12 & 4.5 & 0 & 2.0 & 0 & 0 & 0 & 1956 \\
\hline Inconel 718 & 19 & 3 & 0 & 5.0 & 0 & 0 & 0 & 1960 \\
\hline TRW-NASA VIA & 6.1 & 2.0 & 5.8 & 0.5 & 9.0 & 0 & 0.5 & 1968 \\
\hline René 150 & 5 & 1 & 5 & 0 & 6 & 2.2 & 3 & 1978 \\
\hline
\end{tabular}

${ }^{*}$ Approximate year of availability

Table 2. Compositions of selected Nickel-base super alloys [2].

\begin{tabular}{||c|c|c|c|c|c|c|c|c|c|}
\hline \multirow{2}{*}{$\begin{array}{c}\text { Compo- } \\
\text { sition\% }\end{array}$} & $\begin{array}{c}\text { Inconel } \\
718\end{array}$ & $\begin{array}{c}\text { MAR- } \\
\text { M247 }\end{array}$ & $\begin{array}{c}\text { Udimet } \\
700\end{array}$ & $\begin{array}{c}\text { CMS } \\
\text { X-2 }\end{array}$ & $\begin{array}{c}\text { Inconel } \\
713 C\end{array}$ & $\begin{array}{c}\text { PWA } \\
1480\end{array}$ & $\begin{array}{c}\text { Wasp } \\
\text { aloy }\end{array}$ & N-4 & $\begin{array}{c}\text { René } \\
150\end{array}$ \\
\hline $\mathrm{Fe}$ & 19 & - & - & - & - & - & - & - & - \\
\hline $\mathrm{Ni}$ & 53 & 62 & 53 & 66 & 63 & 63 & 58 & 63 & 58 \\
\hline $\mathrm{Co}$ & - & 10 & 19 & 4.6 & - & 5 & 13 & 7.5 & 12 \\
\hline $\mathrm{Cr}$ & 19 & 8.2 & 15 & 8 & 12 & 10 & 19 & 9.2 & 5 \\
\hline $\mathrm{V}$ & - & - & - & - & - & - & - & - & 3 \\
\hline $\mathrm{Nb}$ & 5.2 & - & - & - & 2 & - & - & 0.5 & 0 \\
\hline $\mathrm{Ta}$ & - & 3 & - & 5.8 & 0 & 12 & 0 & 4 & 6 \\
\hline $\mathrm{Mo}$ & 3 & 0.6 & 5.2 & 0.6 & 4.2 & - & 4.3 & 1.6 & 1 \\
\hline $\mathrm{W}$ & - & 10 & - & 7.9 & - & 4 & - & 6 & 5 \\
\hline $\mathrm{Re}$ & - & - & - & - & - & - & - & - & 2.2 \\
\hline $\mathrm{Zr}$ & - & 0.09 & - & - & 0.1 & - & 0.06 & - & 0.03 \\
\hline $\mathrm{Al}$ & 0.6 & 5.5 & 4.3 & 5.6 & 6.1 & 5 & 1.3 & 3.77 & 5.5 \\
\hline $\mathrm{Ti}$ & 0.8 & 1.4 & 3.5 & 0.9 & 0.8 & 1.5 & 3 & 4.25 & - \\
\hline $\mathrm{B}$ & 0.006 & 0.001 & 0.03 & - & 0.012 & - & 0.006 & - & 0.015 \\
\hline $\mathrm{C}$ & 0.05 & 0.006 & 0.08 & 0.005 & 0.12 & - & 0.08 & 0.00 & 0.06 \\
\hline $\mathrm{Hf}$ & - & - & - & - & - & - & - & - & 1.5 \\
\hline
\end{tabular}

\section{NICKEL BASE SUPERALLOY PHASES}

Nickel base superalloys consist of a face-centered cubic (FCC) matrix $(\gamma)$ nickel with coherent intermetallic precipitates, carbides, borides, and other phases dispersed throughout. Generally, about ten different elements are used for alloying. Some are 
used for specific purposes (such as chromium used to increase oxidation resistance) and others for multiple uses (such as aluminum that increases oxidation resistance while acting mainly as a strengthener through the formation of precipitates). A list of alloying additions and their purposes is show Table 3.

The main secondary phases that form are the gamma prime $(\gamma)$ FCC ordered $\mathrm{Ni}_{3}\left(\mathrm{Al}_{2} \mathrm{Ti}\right)$ intermetallic compound and the carbides $\mathrm{MC}, \mathrm{M}_{6} \mathrm{C}, \mathrm{M}_{23} \mathrm{C}_{6}$, and $\mathrm{M}_{7} \mathrm{C}_{23}$, where "M" designates a metal atom. Processing and heat treatments play significant roles in forming these phases. The mechanical properties of superalloys are controlled by three major factors: the amount and morphology of the $\gamma$ phase, the size and morphology of the grains, and the carbide distribution. The high strength of superalloys is mainly due to the gamma prime, $\boldsymbol{\gamma}$, phase that precipitates from solid solution. High strength levels result as $\gamma$ particles impede dislocation movement, and are directly related to the volume fraction and size of $\gamma$ particles. Higher volume fractions of $\gamma$, with an optimum particle size of approximately $0.1 \mathrm{pm}$ in diameter, lead to higher strength levels [5].

\section{Chemical Composition of Nickel Base Superalloy}

Nickel-based alloys can be either solid solution or precipitation strengthened. Solid solutioned strengthened alloys, such as Hastelloy X, are used in applications requiring only modest strength. In the most demanding applications, such as hot sections of gas turbine engines, a precipitation-strengthened alloy is required. Most nickel-based alloys contain $10-20 \% \mathrm{Cr}$, up to $8 \% \mathrm{Al}$ and $\mathrm{Ti}, 5-10 \% \mathrm{Co}$, and small amounts of $\mathrm{B}, \mathrm{Zr}$, and $\mathrm{C}$. Other common additions are Mo, W, Ta, Hf, and Nb.

The elemental additions in nickel base superalloys can be categorized as being:

1. $(\gamma)$ formers (elements that tend to partition to the ( $\gamma$ matrix).

2. $(\gamma)$ formers (elements that partition to the $(\gamma)$ precipitate).

3. Carbide formers.

4. Elements that segregate to the grain boundaries.

Elements which are considered $\gamma$ formers are Group V, VI, and VII elements such as $\mathrm{Co}, \mathrm{Cr}, \mathrm{Mo}, \mathrm{W}, \mathrm{Fe}$. The atomic diameters of these alloys are only $3-13 \%$ different than $\mathrm{Ni}$ (the primary matrix element). $\gamma$ formers come from group III, IV, and $\mathrm{V}$ elements and include $\mathrm{Al}, \mathrm{Ti}, \mathrm{Nb}, \mathrm{Ta}$, $\mathrm{Hf}$. The atomic diameters of these elements differ from $\mathrm{Ni}$ by $6-18 \%$. The main carbide formers are $\mathrm{Cr}, \mathrm{Mo}, \mathrm{W}, \mathrm{Nb}, \mathrm{Ta}, \mathrm{Ti}$. The primary grain boundary elements are B, C, and Zr. Their atomic diameters are 21$27 \%$ different than $\mathrm{Ni}$.

The major phases present in most nickel superalloys are as follows:

- Gamma $(\gamma)$ : The continuous matrix (called gamma) is a face-centered-cubic (FCC) nickel-based austenitic phase that usually contains a high percentage of solid-solution elements such as $\mathrm{Co}, \mathrm{Cr}, \mathrm{Mo}$, and W.

- Gamma Prime $(\gamma)$ : The primary strengthening phase in nickel-based superalloys is $\mathrm{Ni}_{3}(\mathrm{Al}, \mathrm{Ti})$, and is called gamma prime $(\gamma)$. It is a coherently precipitating phase (i.e., the crystal planes of the precipitate are in registry with the gamma matrix) 
Table 3. The roles of various alloying elements in nickel base super alloys [5].

\begin{tabular}{|l|c|c|c|c|c|c|c|c|c|c|c|c|c|c|}
\hline & $\mathrm{Cr}$ & $\mathrm{Al}$ & $\mathrm{Co}$ & $\mathrm{Fe}$ & $\mathrm{Mo}$ & $\mathrm{W}$ & $\mathrm{Ti}$ & $\mathrm{Ta}$ & $\mathrm{Nb}$ & $\mathrm{Hf}$ & $\mathrm{C}$ & $\mathrm{B}$ & $\mathrm{Zr}$ & $\mathrm{Mg}$ \\
\hline $\begin{array}{l}\text { Matrix } \\
\text { strengtheners }\end{array}$ & $\circ$ & & $\circ$ & $\circ$ & $\circ$ & & & & & & & & & \\
\hline $\begin{array}{l}\text { Gama prime } \\
\text { formers }\end{array}$ & & $\circ$ & & & & & $\circ$ & $\circ$ & $\circ$ & & & & & \\
\hline $\begin{array}{l}\text { Carbide } \\
\text { formers }\end{array}$ & $\circ$ & & & & $\circ$ & $\circ$ & $\circ$ & $\circ$ & $\circ$ & $\varrho$ & & & & \\
\hline $\begin{array}{l}\text { Oxide - scale } \\
\text { formers }\end{array}$ & $\circ$ & $\circ$ & & & & & & & & & & & & \\
\hline $\begin{array}{l}\text { Grain boundary } \\
\text { strengtheners }\end{array}$ & & & & & & & & & & $\circ$ & $\circ$ & $\circ$ & $\varrho$ & $\varrho$ \\
\hline
\end{tabular}

with an ordered L12 (FCC) crystal structure. The close match in matrix/precipitate lattice parameter $(\sim 0-1 \%)$ combined with the chemical compatibility allows the $(\gamma)$ to precipitate homogeneously throughout the matrix and have long-time stability. Interestingly, the flow stress of the $(\gamma)$ increases with increasing temperature up to about $650^{\circ} \mathrm{C}\left(1200^{\circ} \mathrm{F}\right)$. In addition, $(\gamma)$ is quite ductile and thus imparts strength to the matrix without lowering the fracture toughness of the alloy. Aluminum and titanium are the major constituents and are added in amounts and mutual proportions to precipitate a high volume fraction in the matrix. In some modern alloys the volume fraction of the $(\gamma)$ precipitate is around $70 \%$. There are many factors that contribute to the hardening imparted by the $\left(\gamma^{\prime}\right)$ and include $(\gamma)$ fault energy, $(\gamma)$ strength, coherency strains, volume fraction of $(\gamma)$, and $(\gamma)$ particle size. Extremely small $(\gamma)$ precipitates always occur as spheres. In fact, for a given volume of precipitate, a sphere has 1.24 less surface area than a cube, and thus is the preferred shape to minimize surface energy. With a coherent particle, however, the interfacial energy can be minimized by forming cubes and allowing the crystallographic planes of the cubic matrix and precipitate to remain continuous. Thus as the $(\gamma)$ grows, the morphology can change from spheres to cubes, as shown in Fig. 6, or plates depending on the value of the matrix/precipitate lattice mismatch. For larger mismatch values the critical particle size where the change from spheres to cubes (or plates) occurs is reduced. Coherency can be lost by overaging. One sign of a loss of coherency is directional coarsening (aspect ratio) and rounding of the cube edges. Increasing directional coarsening for increasing (positive or negative) mismatch is also expected.

- Carbides: Carbon, added at levels of 0.05-0.2\%, combines with reactive and refractory elements such as titanium, tantalum, and hafnium to form carbides (e.g., $\mathrm{TiC}, \mathrm{TaC}$, or $\mathrm{HfC}$ ). During heat treatment and service, these begin to decompose and form lower carbides such as $\mathrm{M}_{23} \mathrm{C}_{6}$ and $\mathrm{M}_{6} \mathrm{C}$, which tend to form on the grain boundaries. These common carbides all have an FCC crystal structure. Results vary on whether carbides are detrimental or advantageous to superalloy properties. The general opinion is that in superalloys with grain 
boundaries, carbides are beneficial by increasing rupture strength at high temperature.

- Topologically Close-Packed Phases: These are generally undesirable, brittle phases that can form during heat treatment or service. The cell structure of these phases have close-packed atoms in layers separated by relatively large interatomic distances. The layers of close packed atoms are displaced from one another by sandwiched larger atoms, developing a characteristic "topology." These compounds have been characterized as possessing a topologically closepacked (TCP) structure as shown in Fig. 7. Conversely, Ni3Al (gamma prime) is close-packed in all directions and is called geometrically close-packed (GCP). TCPs ( $\sigma, \mu$, Laves, etc.) usually form as plates (which appear as needles on a single-plane microstructure.) The plate-like structure negatively affects mechanical properties (ductility and creep-rupture.) Sigma appears to be the most deleterious while strength retention has been observed in some alloys containing mu and Laves. TCPs are potentially damaging for two reasons: they tie up $\gamma$ and $\gamma$ strengthening elements in a non-useful form, thus reducing creep strength, and they can act as crack initiators because of their brittle nature. Table 4. summarizes the effects of adding various elements to nickel-base super alloy [6].

\section{SINGLE CRYSTAL TURBINE BLADE}

A major use of nickel-based superalloys is in the manufacture of aero engine turbine blades. A single-crystal blade is free from $\gamma / \gamma$ grain boundaries, boundaries are easy diffusion paths and therefore reduce the resistance of the material to creep deformation. The directionally solidified columnar grain structure has many $\gamma$ grains, but the boundaries are mostly parallel to the major stress axis; the performance of such blades is not as good as the single-crystal blades. However, they are much better than the blade with the equiaxed grain structure, which has the worst creep life. One big advantage of the single-crystal alloys over conventionally cast polycrystalline superalloys is that many of the grain boundary strengthening solutes are removed. This results in an increase in the incipient melting temperature (i.e., localised melting due to chemical segregation). The single-crystal alloys can therefore be heat treated to at temperatures in the range $1240-1330^{\circ} \mathrm{C}$, allowing the dissolution of coarse $\gamma$ which is a remanent of the solidification process. Subsequent heat treatment can therefore be used to achieve a controlled and fine-scale precipitation of $\gamma$. The primary reason why the first generation of single-crystal superalloys could be used at higher temperatures than the directionally solidified ones, was because of the ability to heat-treat the alloys at a higher temperature rather than any advantage due to the removal of grain boundaries. A higher heattreatment temperature allows all the $\gamma$ to be taken into solution and then by aging, to precipitate in a finer form, Fig. 8. and Fig. 9. shows the turbine blade single crystal, directionally solidified columnar grains and equiaxed polycrystalline.

Nickel based superalloy blades are generally made using an investment casting process. A wax model is made, around which a ceramic is poured to make the mould. The image on the left shows a wax assembly for making the mould used in the casting of single-crystal nickel based superalloy turbine blades. The wax is 
Table 4. Role of elements in nickel-base super alloy [6].

\begin{tabular}{|l|l|}
\hline Effect & Nickel base \\
\hline Solid-solution strengtheners & $\mathrm{Co}, \mathrm{Cr}, \mathrm{Fe}, \mathrm{Mo}, \mathrm{W}, \mathrm{Ta}$ \\
\hline Carbide form $\mathrm{MC}$ type & $\mathrm{W}, \mathrm{Ta}, \mathrm{Ti}, \mathrm{Mo}, \mathrm{Nb}$ \\
\hline $\mathrm{M}_{7} \mathrm{C}_{3}$ type & $\mathrm{Cr}$ \\
\hline $\mathrm{M}_{23} \mathrm{C}_{6}$ type & $\mathrm{Cr}, \mathrm{Mo}, \mathrm{W}$ \\
\hline $\mathrm{M}_{6} \mathrm{C}$ type & $\mathrm{Mo}, \mathrm{W}$ \\
\hline Carbonitrides $\mathrm{M}(\mathrm{CN})$ type & $\mathrm{C}, \mathrm{N}$ \\
\hline Raises solvus temperature of $\gamma^{\prime}$ & $\mathrm{Co}$ \\
\hline Hardening precipitates and/or intermetallics & $\mathrm{Al}, \mathrm{Ti}, \mathrm{Nb}$ \\
\hline Forms $\gamma^{\prime \prime}$ (Ni3Nb) & $\mathrm{Nb}$ \\
\hline Oxidation resistance & $\mathrm{Al}, \mathrm{Cr}$ \\
\hline Improves hot corrosion resistance & $\mathrm{La}, \mathrm{Th}$ \\
\hline Sulfidation resistance & $\mathrm{Cr}$ \\
\hline Increases rupture ductility & $\mathrm{B}^{*}, \mathrm{Zr}$ \\
\hline Causes grain-boundary segregation & $\mathrm{B}, \mathrm{C}, \mathrm{Zr}$ \\
\hline
\end{tabular}

*If present in large amounts, Borides are formed.

removed from the solid ceramic and molten metal poured in to fill the mould. The actual process is more complicated because of the intricate shape of the blade, with its cooling channels and other features. The image on the right shows the ceramic mould for the simultaneous casting of several blades. The metal is poured in from the top and feeds into the blade sections from the bottom [4].

\section{GENERATIONS FOR SINGLE CRYSTAL NICKEL BASED SUPERALLOYS}

\section{First, Second and Third Generation Superalloys}

The single-crystal superalloys are often classified into first, second and third generation alloys. The second and third generations contain about $3 w t \%$ and $6 w t \%$ of rhenium respectively. Rhenium is a very expensive addition but leads to an improvement in the creep strength and fatigue resistance. It is argued that some of the enhanced resistance to creep comes from the promotion of rafting by rhenium, which partitions into the $\gamma$ and makes the lattice misfit more negative. Atomic resolution experiments have shown that the Re occurs as clusters in the $\gamma$ phase. It is also claimed that rhenium reduces the overall diffusion rate in nickel based superalloys. Table 5 shows the nominal compositions of Single-Crystal Superalloys whereas, Figs. 10 to 13 show bars charts for the essential compositional differences between the first, second and third generation single-crystal superalloys. The generations are separated by gaps in the horizontal axes [7]. 
Table 5. The nominal compositions of Single-Crystal Superalloys [7].

\begin{tabular}{|l|c|c|c|c|c|c|c|c|c|c|c||}
\hline & $\mathrm{Cr}$ & $\mathrm{Co}$ & $\mathrm{Mo}$ & $\mathrm{W}$ & $\mathrm{Ta}$ & $\mathrm{V}$ & $\mathrm{Nb}$ & $\mathrm{Al}$ & $\mathrm{Ti}$ & $\mathrm{Hf}$ & $\mathrm{Re}$ \\
\hline 1st Generation & & & & & & & & & & & \\
\hline PWA1480 & 10 & 5 & 0 & 4 & 12 & & & 5 & 1.5 & 0 & \\
\hline Rene N4 & 9 & 8 & 2 & 6 & 4 & & 0.5 & 3.7 & 4.2 & 0 & \\
\hline SRR99 & 8 & 5 & 0 & 10 & 3 & & & 5.5 & 2.2 & 0 & \\
\hline RR2000 & 10 & 15 & 3 & 0 & 0 & 1 & & 5.5 & 4 & 0 & \\
\hline AM1 & 8 & 6 & 2 & 6 & 9 & & & 5.2 & 1.2 & 0 & \\
\hline AM3 & 8 & 6 & 2 & 5 & 4 & & & 6 & 2 & 0 & \\
\hline CMSX2 & 8 & 5 & 0.6 & 8 & 6 & & & 5.6 & 1 & 0 & \\
\hline CMSX3 & 8 & 5 & 0.6 & 8 & 6 & & & 5.6 & 1 & 0.1 & \\
\hline CMSX6 & 10 & 5 & 3 & 0 & 2 & & & 4.8 & 4.7 & 0.1 & \\
\hline AF56 & 12 & 8 & 2 & 4 & 5 & & & 3.4 & 4.2 & 0 & \\
\hline 2nd Generation & & & & & & & & & & & \\
\hline CMSX4 & 7 & 9 & 0.6 & 6 & 7 & & & 5.6 & 1 & 0.1 & 3 \\
\hline PWA1484 & 5 & 10 & 2 & 6 & 9 & & & 5.6 & 0 & 0.1 & 3 \\
\hline SC180 & 5 & 10 & 2 & 5 & 9 & & & 5.2 & 1 & 0.1 & 3 \\
\hline MC2 & 8 & 5 & 2 & 8 & 6 & & & 5 & 1.5 & 0 & 0 \\
\hline Rene N5 & 7 & 8 & 2 & 5 & 7 & & & 6.2 & 0 & 0.2 & 3 \\
\hline 3rd Generation & & & & & & & & & & & \\
\hline CMSX10 & 2 & 3 & 0.4 & 5 & 8 & & & 5.7 & 0.2 & 0.03 & 6 \\
\hline Rene N6 & 4.2 & 12.5 & 1.4 & 6 & 7.2 & & 0.1 & 5.75 & 0 & 0.15 & 5.4 \\
\hline TMS75 & 3 & 12 & 2 & 6 & 6 & & & 6 & 0 & 0.1 & 5 \\
\hline TMS113 & 2.89 & 11.9 & 1.99 & 5.96 & 5.96 & & & 6.56 & 0 & 0.1 & 5.96 \\
\hline & $\mathrm{Cr}$ & $\mathrm{Co}$ & $\mathrm{Mo}$ & $\mathrm{W}$ & $\mathrm{Ta}$ & $\mathrm{V}$ & $\mathrm{Nb}$ & $\mathrm{Al}$ & $\mathrm{Ti}$ & $\mathrm{Hf}$ & $\mathrm{Re}$ \\
\hline
\end{tabular}

\section{Fourth Generation Superalloys}

The addition of rhenium offers the prospect of significant improvements in the phase stability and creep resistance of advanced superalloys. The question is how to exploit this potential to greatest effect. For many years it was collaborated on the development of single crystal superalloys and have recently played a major role in the development and patenting of the improved second-generation superalloy. The aim is to improve the intrinsic temperature capability of current alloys by $35^{\circ} \mathrm{C}$ which will result in considerable increases in engine efficiency [8].

\section{EXPERIMENTAL INVESTIGATION}

\section{Materials}

The materials under investigation are three alloy scraps; these alloys were chemically analyzed by using spectrometer device, the chemical compositions of 
these alloys used in the experiments illustrated in Table 6. The features of these scrap alloys in the three heats are as follows:-

Alloy Scrap (1): is a Scrap turbine wheel of gas turbine engine has German standard symbol "G-NiCr13Al6MoNb" DIN No. (2.4670) nickel base superalloy.

Alloy Scrap (2): is a scrap turbine blade of gas turbine engine has German standard symbol "NiCr20Co13Mo4Ti3Al" DIN No. (2.4654) nickel base superalloy.

Alloy Scrap (3): is a scrap compressor blades of gas turbine engine this alloy is titanium base superalloy.

The mechanical properties of three scrap alloys were determined by using universal hardness testing machine for hardness test while the tensile properties were determined from the DIN standard and also empirically calculated using MAP online (Materials Algorithm Project) at http://www-map-online.msm.cam.ac.uk, by entering their chemical composition, the results are illustrated Table 7.

\section{Charge Calculation}

The furnace charge consisted of scrap alloy (1), (2), (3) and steel scraps with ferro chromium $\mathrm{Fe}-\mathrm{Cr}$, the charge calculations made by using the following equation:-

$$
[a]=[M][C]
$$

where matrix a is final chemical composition, matrix $M$ is charge chemical analyses and matrix $\mathrm{C}$ is charge mix. The calculations and results are as follows:-

1) $50 \%$ of scrap alloy (2) added to $50 \%$ of scrap alloy (1) to produce a nickel base superalloy with higher cobalt content called product alloy (2), as shown in the following equation:-

$\left[\begin{array}{cc}71.8 & 63.3 \\ 11.9 & 10.7 \\ 6.5 & 4.5 \\ 1.68 & 0.29 \\ 0.81 & 0.1 \\ 0.25 & 0.025 \\ 0.041 & 0.029 \\ 3.55 & 3 \\ 0.004 & 1 \\ 0.024 & 0.13 \\ 0.008 & 0.013 \\ 0.005 & 0.004 \\ 1 & 13.6 \\ 2.44 & 2.92\end{array}\right]\left[\begin{array}{l}0.5 \\ 0.5\end{array}\right]=\left[\begin{array}{c}67.55 \\ 11.3 \\ 5.5 \\ 0.985 \\ 0.455 \\ 0.1375 \\ 0.035 \\ 3.275 \\ 0.502 \\ 0.077 \\ 0.0105 \\ 0.0045 \\ 7.3 \\ 2.68\end{array}\right]$

2) $2-10 \%$ of scrap alloy (3) added to $90 \%$ of product alloy (2) to produce a nickel base superalloy with higher titanium content called product alloy (3), as shown in the following equation:- 
Table 6. Chemical analyses of alloys used in the experiments.

\begin{tabular}{|c|c|c|c|}
\hline Materials & Alloy Scrap (1) & Alloy Scrap (2) & Alloy Scrap (3) \\
\hline Elements & Wt. \% & Wt. \% & Wt. \% \\
\hline $\mathrm{Ni}$ & 71.8 & 63.3 & - \\
\hline $\mathrm{Cr}$ & 11.9 & 10.7 & 0.1 \\
\hline $\mathrm{Al}$ & 6.5 & 4.5 & 2.9 \\
\hline $\mathrm{Nb}$ & 1.68 & 0.29 & - \\
\hline $\mathrm{Fe}$ & 0.81 & 0.1 & 1.9 \\
\hline $\mathrm{Si}$ & 0.25 & 0.025 & - \\
\hline $\mathrm{Mn}$ & 0.041 & 0.029 & 0.076 \\
\hline $\mathrm{Mo}$ & 3.55 & 3 & - \\
\hline $\mathrm{V}$ & 0.004 & 1.0 & 12.3 \\
\hline $\mathrm{W}$ & 0.024 & 0.13 & - \\
\hline $\mathrm{Cu}$ & 0.008 & 0.013 & 0.46 \\
\hline $\mathrm{C}$ & 0.005 & 0.004 & 0.03 \\
\hline $\mathrm{Co}$ & 1.0 & 13.6 & 0.64 \\
\hline $\mathrm{Ti}$ & 2.44 & 2.92 & 81.6 \\
\hline
\end{tabular}

Table 7. Mechanical properties of alloys used in the experiments.

\begin{tabular}{|l|c|c|c||}
\hline Materials & $\begin{array}{c}\text { Scrap } \\
\text { alloy (1) }\end{array}$ & $\begin{array}{c}\text { Scrap } \\
\text { alloy (2) }\end{array}$ & $\begin{array}{c}\text { Scrap } \\
\text { alloy (3) }\end{array}$ \\
\hline ultimate Tensile strength (MPa) & 850 & 1010 & 1040 \\
\hline Yield strength* (MPa) & 733 & 855 & 970 \\
\hline Elongation \% & 3 & 5 & 4.5 \\
\hline Hardiness (HV) & 380 & 385 & 340 \\
\hline
\end{tabular}

*yield strength $0.2 \%$ offset

$\left[\begin{array}{cc}67.55 & 0 \\ 11.3 & 0.1 \\ 5.5 & 2.9 \\ 0.985 & 0 \\ 0.455 & 1.9 \\ 0.1375 & 0 \\ 0.035 & 0.076 \\ 3.275 & 0 \\ 0.502 & 12.3 \\ 0.077 & 0 \\ 0.0105 & 0.46 \\ 0.0045 & 0.03 \\ 7.3 & 0.64 \\ 2.68 & 81.6\end{array}\right]\left[\begin{array}{l}0.9 \\ 0.1\end{array}\right]=\left[\begin{array}{c}60.795 \\ 10.18 \\ 5.24 \\ 0.8865 \\ 0.5995 \\ 0.12375 \\ 0.0391 \\ 2.9475 \\ 1.6818 \\ 0.05545 \\ 0.00705 \\ 0.00705 \\ 6.634 \\ 10.572\end{array}\right]$

3) $50 \%$ of steel scrap and $10 \%$ Fe-Cr added to $40 \%$ of product alloy (3) aiming to produce iron base superalloy type $\mathrm{Fe}-\mathrm{Ni}-\mathrm{Cr}$ this alloy called product alloy (4), as shown in the following equation:- 


$\left[\begin{array}{ccc}60.795 & 0 & 0 \\ 10.18 & 0 & 64 \\ 5.24 & 0 & 0 \\ 0.8865 & 0 & 0 \\ 0.5995 & 99.85 & 35.95 \\ 0.12375 & 0.05 & 0 \\ 0.0391 & 0.08 & 0 \\ 2.9475 & 0 & 0 \\ 1.6818 & 0 & 0 \\ 0.05545 & 0 & 0 \\ 0.00705 & 0 & 0 \\ 0.00705 & 0.02 & 0.05 \\ 6.634 & 0 & 0 \\ 10.572 & 0 & 0\end{array}\right]\left[\begin{array}{l}0.4 \\ 0.5 \\ 0.1\end{array}\right]=\left[\begin{array}{c}24.313 \\ 10.472 \\ 2.095 \\ 0.3545 \\ 53.7593 \\ 0.0745 \\ 0.05564 \\ 1.179 \\ 0.57272 \\ 0.02772 \\ 0.02218 \\ 0.01782 \\ 2.5536 \\ 4.2283\end{array}\right]$

From the previous result, the expected chemical composition of product alloy (4) is shown in Table 8.

\section{Casting Procedure}

The scrap alloys were prepared by melting in a coreless main frequency induction furnace $(100 \mathrm{Kg})$. The furnace lining was chosen to be (alumina). The melting and casting process was performed according to the following steps:-

1) Preparing the sand mold cavity with the desired shapes.

2) Putting $35 \mathrm{~kg}$ of the prepared scrap alloy (1) in the furnace.

3) Heating the furnace with slow initial rates to prevent alloy thermal shock, then Furnace heated to casting temperature $1500^{\circ} \mathrm{C}$ (above melting temperature of pure nickel $1453^{\circ} \mathrm{C}$ ).

4) The furnace temperature was held at the casting temperature for 15 minutes to ensure homogeneous composition.

5) A sample from the furnace was poured in a cubic mold shape its dimensions are $11.5 \times 4 \times 1.5 \mathrm{~cm}$, this sample called product alloy (1).

6) Adding $35 \mathrm{~kg}$ of alloy scrap (2) to product alloy (1) in the furnace, after 15 minutes of melting, a sample was poured in a stepped mold shape with three different thicknesses (A\&B\&C), thickness $A$ equal $3.9 \mathrm{Cm}$, thickness $B$ equal $2.6 \mathrm{Cm}$, and thickness $\mathrm{C}$ equal $1.5 \mathrm{Cm}$, this sample called product alloy (2). This stepped cast specimen was made to study the influence of solidification rate on mechanical properties.

7) Adding $7 \mathrm{~kg}$ of alloy scrap (3) to product alloy (2) in the furnace, after 5 minutes of melting, a Samples was poured in a molds have a cylindrical shapes, each mold has diameter $3 \mathrm{~cm}$ and height $16 \mathrm{~cm}$, this sample called product alloy (3).

8) Adding $50 \mathrm{~kg}$ steel scrap with $10 \mathrm{~kg}$ Ferro chrome (Fe- $\mathrm{Cr}$ ) to product alloy (3) in the furans aiming to produce iron base superalloy, after 20 minuets of melting, samples were poured in cubic shape molds each one has dimensions of $11.5 \times 4 \times 1.5 \mathrm{~cm}$, these samples called product (4). 
Table 8. Calculated chemical composition of product alloy (4).

\begin{tabular}{|c|c|c|c|c|c|c|c|c|c|c|c|c|c|c|}
\hline $\begin{array}{c}\text { Elem } \\
\text {-ents }\end{array}$ & $\mathrm{Ni}$ & $\mathrm{Cr}$ & $\mathrm{Al}$ & $\mathrm{Nb}$ & $\mathrm{Fe}$ & $\mathrm{Si}$ & $\mathrm{Mn}$ & $\mathrm{Mo}$ & $\mathrm{V}$ & $\mathrm{W}$ & $\mathrm{Cu}$ & $\mathrm{C}$ & $\mathrm{Co}$ & $\mathrm{Ti}$ \\
\hline $\begin{array}{c}\text { Wt. } \\
\%\end{array}$ & 24.31 & 10.74 & 2.1 & 0.355 & 53.76 & 0.075 & 0.056 & 1.18 & 0.57 & 0.03 & 0.022 & 0.018 & 2.55 & 4.23 \\
\hline
\end{tabular}

\section{RESULTS AND DISCUSSION}

\section{Chemical Analyses of the Samples under Investigation}

The product alloys in as cast conditions were prepared for chemical analyses by cutting and surface grinding. Spectrometer device type spectroport was used to investigate chemical compositions of product alloys as shown in Table 9.

The results of product alloys chemical compositions are as follows:-

Product Alloy (1): Is nickel base superalloy and has equivalent standard in Germany designation (DIN) Material No. (2.4670), Symbol: G-iCr13Al6MoNb. The chemical compositions of product alloy (1) is similar to chemical composition of scrap alloy (1).

Product Alloy (2): Is nickel base superalloy, and has equivalent standard in Germany designation (DIN) Material No. (2.4654), symbol: NiCr20Co13Mo4Ti3Al. The main difference in chemical compositions from product alloy (1) and product alloy (2) is in cobalt percent content, so the effect of cobalt content on the mechanical properties and microstructure of nickel base alloy could be studded in product alloy (2).

Product Alloy (3): Is nickel base superalloy with high titanium percent content (10.78 $\%)$. The main difference in chemical compositions of product alloy (3) and product alloy (2) is titanium content, so the effect of titanium on the mechanical properties and microstructure of nickel base alloy could studded in product alloy (3).

Product Alloy (4): Is iron base superalloy, the equivalent standard in Germany designation (DIN) is material No. (1.4944) symbol: X10CrNiCoN22-20-18, ASTM 660.

\section{Mechanical Properties of the Product Alloys}

The product alloys in as cast conditions were prepared for measuring their mechanical properties by cutting and machining according to the ASTM standards. Universal tensile testing machine and the universal hardness testing machine were used for measuring product alloys tensile tests and hardness consequently. The mechanical properties of the product alloys illustrated in Table 10. This table includes results for three different thicknesses of product alloy (2).

The mechanical properties results of product alloy (1) and (2) show that the ultimate tensile strength, yield strength and hardness for product alloy (2) is higher than these for product alloy (1), on the other hand chemical composition results show that the 
Table 9. Chemical analyses of the product alloys.

\begin{tabular}{|c|c|c|c|c|}
\hline Materials & $\begin{array}{c}\text { Product alloy } \\
(1)\end{array}$ & $\begin{array}{c}\text { Product alloy } \\
(2)\end{array}$ & $\begin{array}{c}\text { Product alloy } \\
(3)\end{array}$ & $\begin{array}{c}\text { Product alloy } \\
(4)\end{array}$ \\
\hline Elements & Wt. \% & Wt. \% & Wt. \% & Wt. \% \\
\hline $\mathrm{Ni}$ & 72.4 & 68.6 & 57 & 24.3 \\
\hline $\mathrm{Cr}$ & 13.8 & 12.25 & 12.8 & 13.2 \\
\hline $\mathrm{Al}$ & 3.4 & 2.23 & 1.2 & 0.2 \\
\hline $\mathrm{Nb}$ & 1.68 & 0.86 & 1.26 & 0.6 \\
\hline $\mathrm{Fe}$ & 0.83 & 0.46 & 2 & 45.77 \\
\hline $\mathrm{Si}$ & 0.25 & 0.19 & 0.15 & 0.78 \\
\hline $\mathrm{Mn}$ & 0.041 & 0.035 & 0.04 & 0.46 \\
\hline $\mathrm{Mo}$ & 4 & 3.07 & 2.82 & 1.53 \\
\hline $\mathrm{V}$ & 0.056 & 0.52 & 1.05 & 0.35 \\
\hline $\mathrm{W}$ & 0.024 & 0.077 & 1.99 & 0.98 \\
\hline $\mathrm{Cu}$ & 0.006 & 0.021 & 0.032 & 0.11 \\
\hline $\mathrm{C}$ & 0.005 & 0.004 & 0.003 & 0.08 \\
\hline $\mathrm{Co}$ & 1.08 & 9.31 & 9.37 & 5.05 \\
\hline $\mathrm{Ti}$ & 2.44 & 2.68 & 10.78 & 6.6 \\
\hline \hline
\end{tabular}

Table 10. Mechanical properties of the product alloys under investigation.

\begin{tabular}{|c|c|c|c|c|c|c|}
\hline \multirow{2}{*}{ Materials } & \multirow{2}{*}{$\begin{array}{l}\text { product } \\
\text { alloy } \\
\text { (1) }\end{array}$} & \multicolumn{3}{|c|}{ product alloy (2) } & \multirow{2}{*}{$\begin{array}{l}\text { product } \\
\text { alloy (3) }\end{array}$} & \multirow{2}{*}{$\begin{array}{l}\text { product } \\
\text { alloy(4) }\end{array}$} \\
\hline & & $\begin{array}{c}\text { Thickness } \\
\text { A }\end{array}$ & $\begin{array}{c}\text { Thickness } \\
\text { B }\end{array}$ & $\begin{array}{c}\text { Thickness } \\
\text { C }\end{array}$ & & \\
\hline $\begin{array}{l}\text { ultimate Tensile } \\
\text { strength (MPa) }\end{array}$ & 940 & 950 & 955 & 980 & 1050 & 600 \\
\hline $\begin{array}{l}\text { Yield strength* } \\
(\mathrm{MPa})\end{array}$ & 813 & 825 & 830 & 955 & 980 & 410 \\
\hline Elongation \% & 4.2 & 4.4 & 4.5 & 5.2 & 5.5 & 16 \\
\hline Hardiness (HV) & 380 & 384 & 385 & 388 & 500 & 315 \\
\hline
\end{tabular}

*yield strength $0.2 \%$ offset.

main difference is in cobalt content, which equal $(9.31 \% \mathrm{Co})$ in product alloy (2) and $(1.08 \% \mathrm{Co})$ in product alloy (1). These results indicate that the increased cobalt content in product alloy (2) leads to increase its ultimate tensile strength, yield strength and hardness.

The mechanical properties results of product alloy (2) and (3) show that the ultimate tensile strength, yield strength and hardness for product alloy (3) is higher than these 
for product alloy (2), on the other hand chemical composition results show that the main difference is in titanium content, which equal (10.78\% Ti) in product alloy (3) and $(2.68 \% \mathrm{Ti})$ in product alloy (2). These results indicate that the increased titanium content in product alloy (3) leads to increase its ultimate tensile strength, yield strength and hardness.

Product alloy (4) is iron base superalloy type Fe-Ni-Cr with nickel content $(24.3 \% \mathrm{Ni})$ and chromium content $(13.2 \% \mathrm{Cr})$. The mechanical properties results of product alloy (4) show that the ultimate tensile strength equal $600 \mathrm{Mpa}$, this result means that this alloy has high ultimate tensile strength that near to that of high cost nickel base superalloy which could be used in production of small gas turbine engine blades (microturbines).

Product alloy (2) has a stepped shape with three different thicknesses (A\&B\&C), thickness $A$ equal $3.9 \mathrm{Cm}$, thickness $B$ equal $2.6 \mathrm{Cm}$, and thickness $C$ equal $1.5 \mathrm{Cm}$. These three different thicknesses were produced to study the solidification behavior of this alloy. The results show that the ultimate tensile strength, yield strength and hardness of thinner thickness $C$ are higher than those of thickness $A$ and $B$, the ultimate tensile strength, yield strength and hardness of thickness $B$ are higher than those of thickness $A$. These results indicate that the ultimate tensile strength, yield strength and hardness of nickel base superalloy could be improved by decreasing thickness of nickel base superalloy. By other word, increase the solidification rate of nickel base superalloy, result in increase of the ultimate tensile strength, yield strength and hardness.

The chemical compositions and the ultimate tensile strength, yield strength and hardness results of product alloy (1) are similar to those of base material scrap alloy (1). These results indicate that scrap turbine blades of gas turbine engines can be reused for production of new turbine blades; this process has a great economic benefits.

\section{Microstructure Investigation}

Inverted Olympus microscope equipped with digital camera used to fix the captured microstructures. A coupon of product alloys 1, 2, 3 and 4 were prepared for optical microscopy by grinding, polishing according to standard techniques and then etching using $10 \mathrm{ml}$ of nitric acid, $20 \mathrm{ml}$ of hydrochloric acid, $20 \mathrm{ml}$ glycerol, $10 \mathrm{ml}$ hydrogen peroxide at room temperature for a time 2-2.5 $\mathrm{min}$.

Figures 14 and 15 show the microstructure of product alloy (1) and product alloy (2) which are nickel base superalloys. It shows the continuous matrix $(\gamma)$ is a facecentered-cubic (FCC) nickel-based austenitic phase. The primary strengthening phase $\left(\gamma^{\prime}\right)$ is Ni3(Al,Ti), It is a coherently precipitating phase. The dendrites of $\left(\gamma^{\prime}\right)$ particles could be seen clearly.

Figure 16 shows the microstructure of product alloy (3) which is nickel base superalloy austenitic structure FCC with elements such as $\mathrm{Co}, \mathrm{Cr}$ that considered $\gamma$ formers. The increased in titanium content leads to form carbides (TiC), the presence of carbides enhances mechanical properties by preventing grain boundary 
sliding. The increased in titanium content also change the microstructure from dendrite structure to a fine cellular one.

Figure 17 shows the microstructure of product alloy (4) which is iron base superalloy type $\mathrm{Fe}-\mathrm{Ni}-\mathrm{Cr}$, the microstructure is austenitic content in the matrix with $\gamma^{\prime}$ precipitation strengthening, $\mathrm{Ni}$ stabilizes the austenitic phase of matrix and also increase strength. $\mathrm{Cr}$ content increasing structure stability. Mo and w are elements serve for solid solution strengthening of austenite matrix. Ti combines with $\mathrm{Ni}$ as well as $\mathrm{Al}$ and $\mathrm{Nb}$ and causes precipitation of $\gamma^{\prime}$ phase and increase strength. Carbides are represented as small particles, carbon combines with $\mathrm{Ti}$ and $\mathrm{Nb}$ so as to improve ductility. Fe-base superalloy which is excellent in high-temperature strength and structural stability used for gas turbine engine parts, heat resistant tools and hot forging dies, the grain boundaries could be seen.

\section{CONCLUSIONS}

Recycle of scrap turbine blades of gas turbine engines for production of turbine blades. This process used to reduce the coast of production of nickel based turbine blades by using scrap turbine blades.

The addition of cobalt and titanium percent content in nickel base superalloy is to increase in ultimate strength, yield strength and hardness, however improve the mechanical properties.

The mechanical properties of nickel base super alloy improved by increasing solidification rate so increase the ultimate strength, yield strength and hardness by decreasing thickness of the produced shapes.

Produce a steel alloy with nickel content (24.3\%) and chromium content (13.2\%), which called iron base superalloy (product alloy 4) for production of turbine blades, the results of the ultimate tensile strength is $600 \mathrm{MPa}$. This alloy could used for production of turbine blades for small gas turbine engines and land base turbine engine generators, which called microturbine however; this process used to reduce the coast of production of turbine blades from steel instead of nickel base superalloy.

The microstructure of nickel base alloys shows the continuous matrix $(\gamma)$ is a facecentered-cubic (FCC) and also the primary strengthening phase $\left(\gamma^{\prime}\right)$, the microstructure change from dendrite structure to a fine cellular one by increasing titanium percent content.

The microstructure of iron base superalloy is austenitic content in the matrix with $\gamma^{\prime}$ precipitation strengthening with grain boundaries, the carbides is represented as small particles.

The importance of Nickel base turbine blades is to increase Turbine Inlet Temperature (TIT) in gas turbine engines allow the turbine to operate more efficiently by withstanding higher temperatures. 
Nickel base turbine blades structure are equiaxed polycrystalline, directionally solidified columnar grains and single crystal turbine blades. The big advantage of the single-crystal turbine blades types over conventionally cast polycrystalline superalloys is that many of the grain boundary strengthening solutes are removed, this increase the resistance of the material to creep deformation and could be used at higher temperatures.

The mechanical properties of superalloys are controlled by three major factors: the amount and morphology of the $\gamma$ phase, the size and morphology of the grains, and the carbide distribution. The high strength of superalloys is mainly due to the gamma prime $\boldsymbol{\gamma}$, phase that precipitates from solid solution. High strength levels result as $\gamma$ particles impede dislocation movement, and are directly related to the volume fraction and size of $\gamma^{\prime}$ particles.

\section{REFERENCES}

[1] C. T. Sims, Stolloff, Norman S., Hagel and William C, "Superalloys II," 1987.

[2] J. R. Stephens, "The Superalloys, Strategic Materials Availability and Supply, Properties and Selection," ASM Handbook vol. 1, 1993.

[3] M. Cervenka, "The Rolls-Royce Trent Engine," 2000.

[4] H. K. D. H. Bhadeshia, "Nickel base superalloys," 2003.

[5] H. M. J. S. a. B. Eng, "The Processing of Gas Turbine Engine Hot Section Materials Through Directional Solidification," 1999.

[6] W. L. M. a. S. Lamb, "Nickel and Nickel Alloys," ASM Handbook, vol. 2, 1992.

[7] H. K. D. H. Bhadeshia, "1st, 2nd and 3rd Generation Single-Crystal Nickel Based Superalloys," 2003.

[8] D. C. Rae, "Mechanical Properties and Microstructure Fourth Generation Superalloys," 2007.

[9] C. M. F. R. a. R. C. Reed, "The precipitation of topologically close-packed phases in rhenium-containing superalloys," 2001.

[10] N. E.-B. a. A. Nofal, "Nickel Superalloy for Investment casting of Turbine Blades," 2007. 


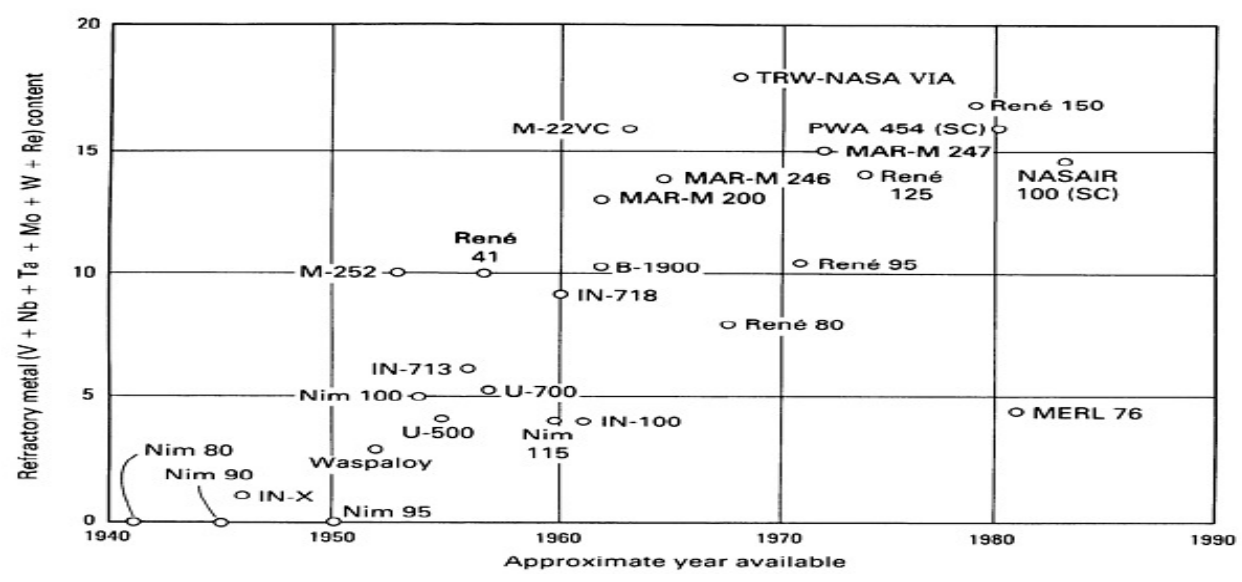

Fig. 1. Increased use of refractory metals in nickel base super alloys [2].

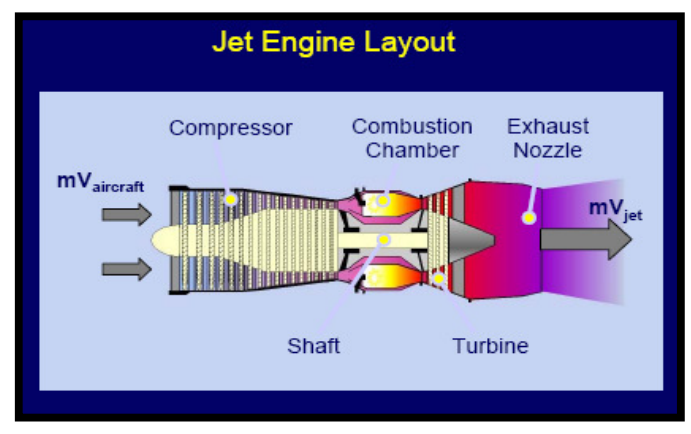

Fig. 2. The layout of the Jet engine [3].

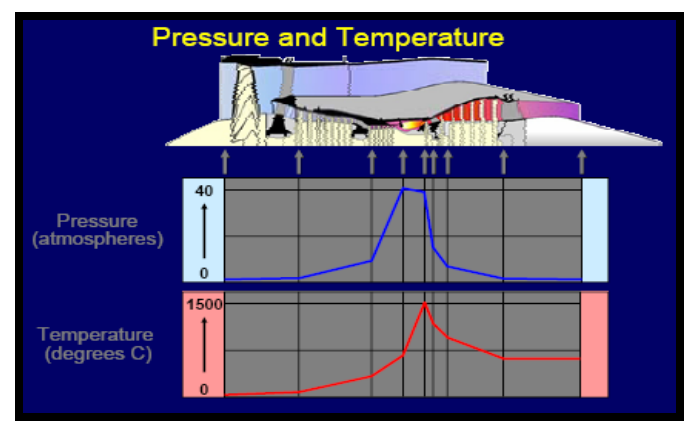

Fig. 3. Pressure and temperature distribution in jet engine [3].

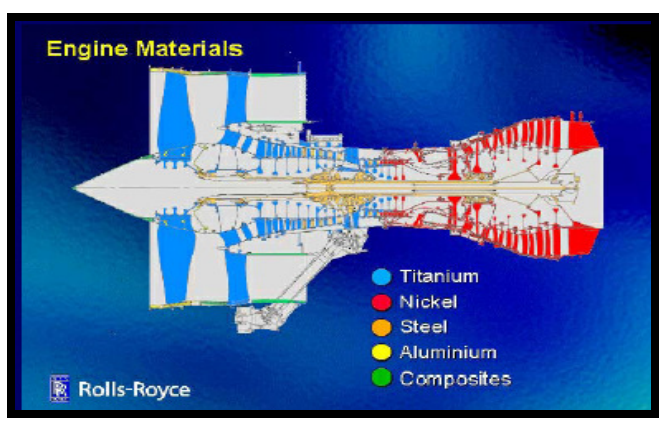

Fig. 4. Materials and alloys positions inside the jet engine [4]. 


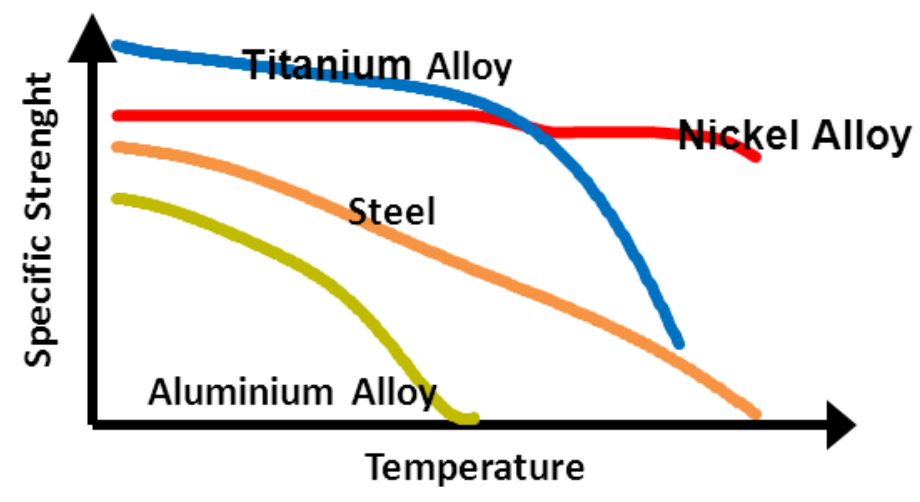

Fig. 5. Specific strength of variant alloys versus temperature [3].

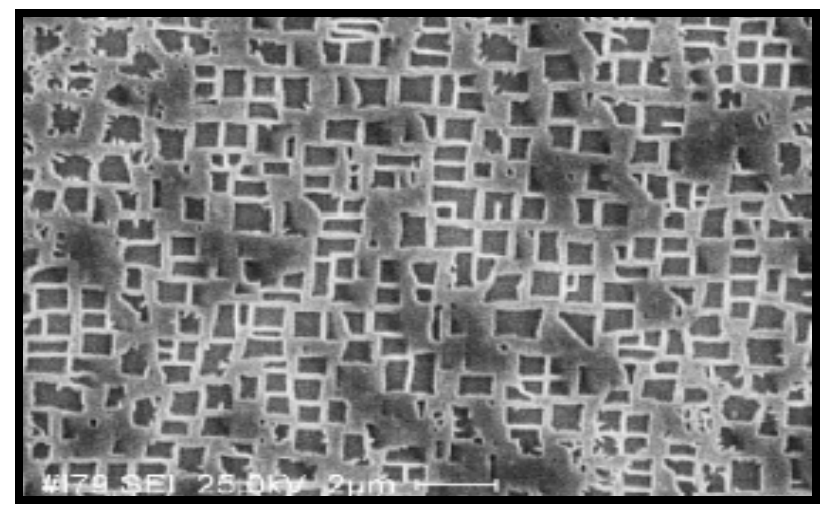

Fig. 6. $\gamma$ precipitates as cubic morphology in $\gamma$ matrix [2].

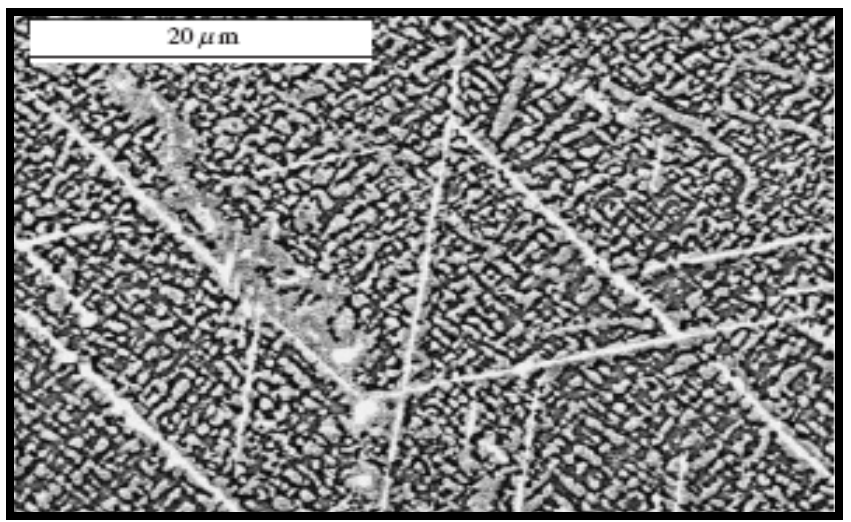

Fig. 7. TCP phases (needle shape) in Ni Base Superalloys [9]. 


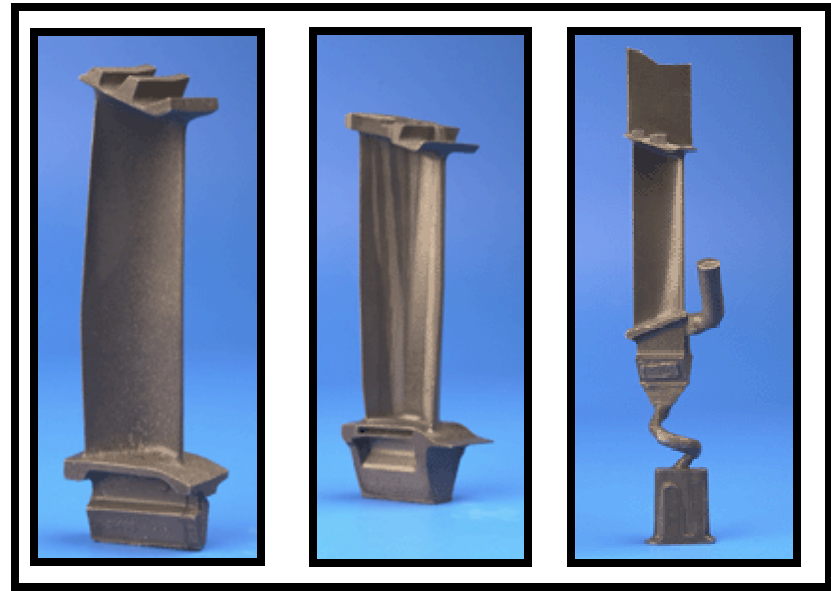

Fig. 8. Turbine blade (from left to right), equiaxed polycrystalline, directionally solidified columnar grains and single crystal [4].

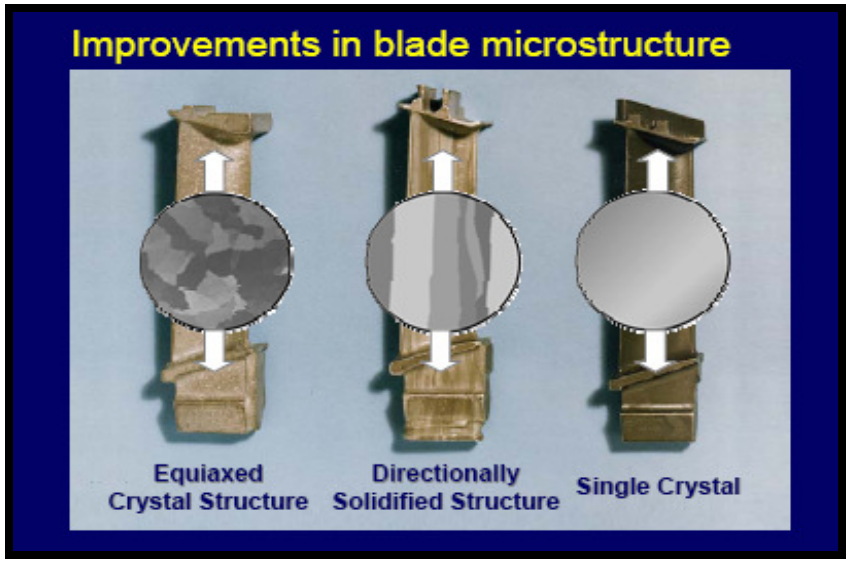

Fig. 9. Structure of Polycrystalline (CC), Directional Solidified (DS) and Single Crystal (SC) [10].

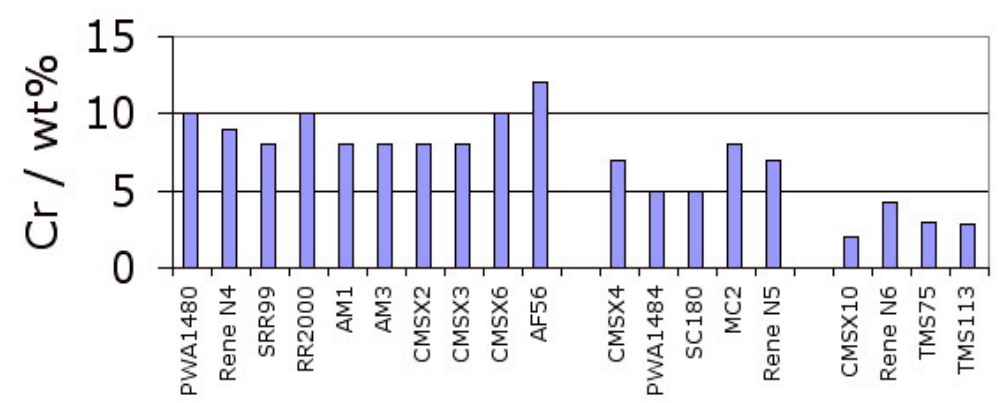

Fig. 10. Bars charts for the chromium difference between the first, second and third generation single-crystal super alloys [7]. 


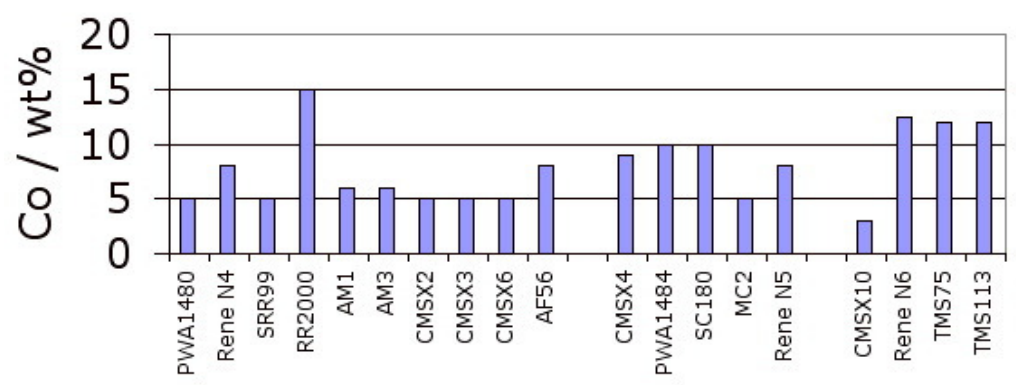

Fig. 11. Bars charts for the cobalt difference between the first, second and third generation single-crystal super alloys [7].

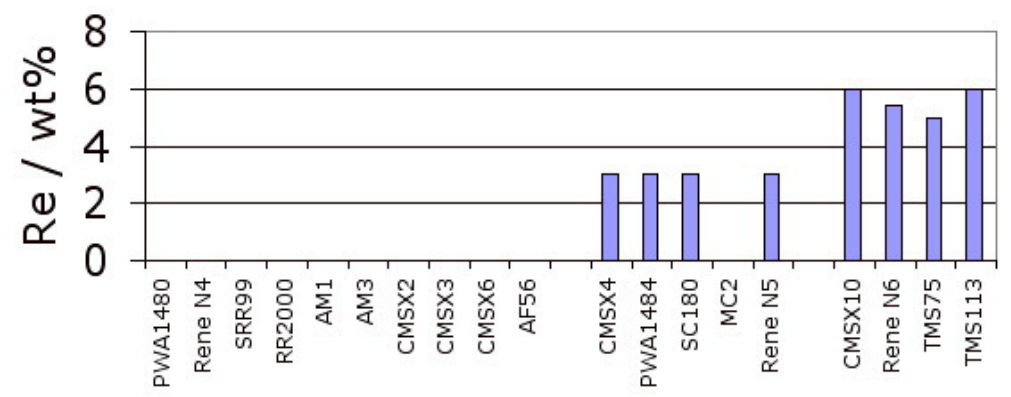

Fig. 12. Bars charts for the rhenium difference between the first, second and third generation single-crystal superalloys.

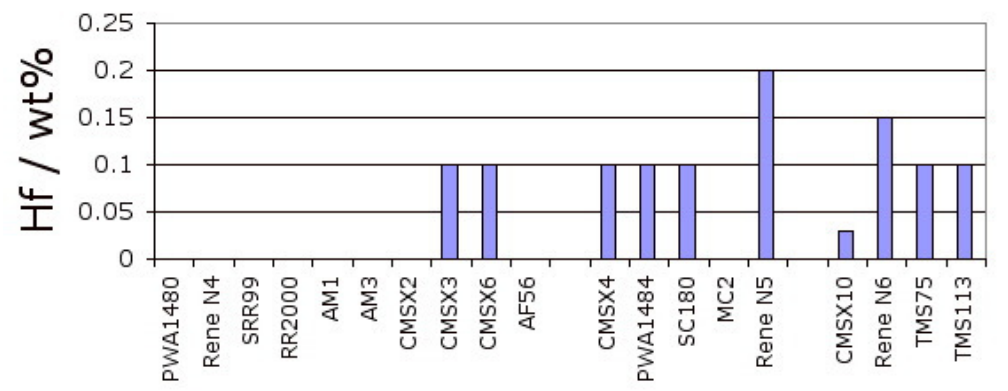

Fig. 13. Bars charts for the hafnium difference between the first, second and third generation single-crystal super alloys [7].

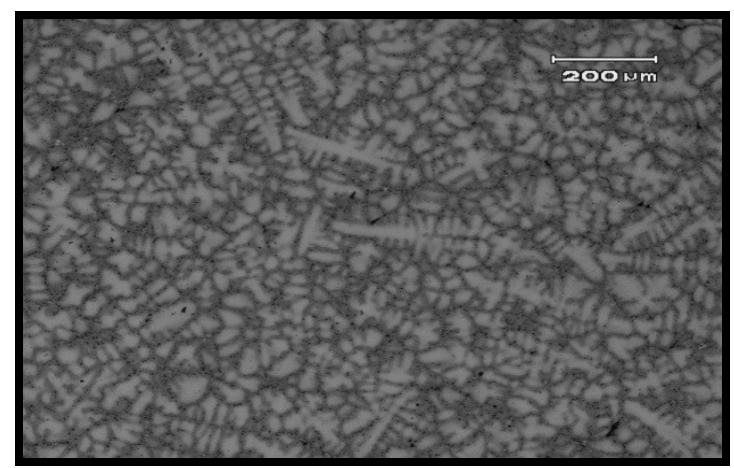

Fig.14. Microstructure of sample (1) (50x). 


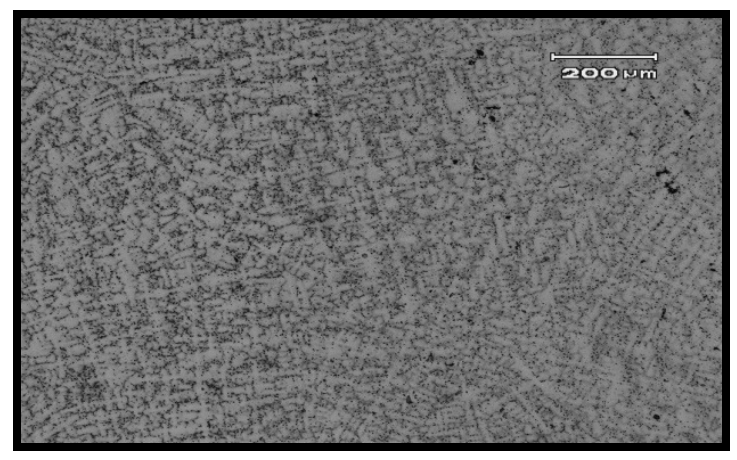

Fig.15. Microstructure of sample (2), (5x).

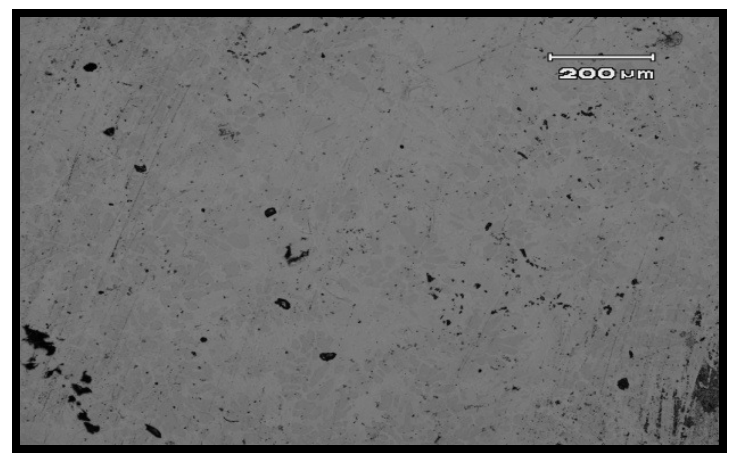

Fig.16. Microstructure of sample (3), (10x).

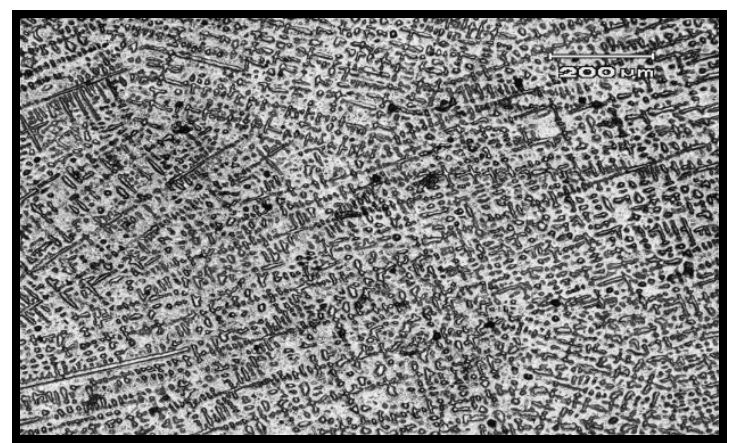

Fig.17. OMicrostructure of sample (4), (5x). 